\title{
First mesospheric turbulence study using coordinated rocket and MST radar measurements over Indian low latitude region
}

\author{
H. Chandra ${ }^{1}$, H. S. S. Sinha ${ }^{1}$, U. Das ${ }^{1}$, R. N. Misra ${ }^{1}$, S. R. Das ${ }^{1}$, J. Datta ${ }^{2}$, S. C. Chakravarty ${ }^{2}$, A. K. Patra ${ }^{3}$, \\ N. Venkateswara Rao ${ }^{3}$, and D. Narayana $\mathrm{Rao}^{3}$ \\ ${ }^{1}$ Physical Research Laboratory, Ahmedabad, India \\ ${ }^{2}$ ISRO Headquarters, Bangalore, India \\ ${ }^{3}$ National Atmospheric Research Laboratory, Tirupati, India \\ Received: 26 October 2007 - Revised: 6 August 2008 - Accepted: 11 August 2008 - Published: 12 September 2008
}

\begin{abstract}
A campaign to study turbulence in the mesosphere, over low latitudes in India, using rocket-borne measurements and Indian MST radar, was conducted during July 2004. A rocket-borne Langmuir probe detected a spectrum of electron density irregularities, with scale sizes in the range of about $1 \mathrm{~m}$ to $1 \mathrm{~km}$, in $67.5-78.0 \mathrm{~km}$ and $84-89 \mathrm{~km}$ altitude regions over a low latitude station Sriharikota $\left(13.6^{\circ} \mathrm{N}\right.$, $\left.80.2^{\circ} \mathrm{E}\right)$. A rocket-borne chaff experiment measured zonal and meridional winds about $30 \mathrm{~min}$ after the Langmuir probe flight. The MST radar located at Gadanki $\left(13.5^{\circ} \mathrm{N}, 79.2^{\circ} \mathrm{E}\right)$, which is about $100 \mathrm{~km}$ west of Sriharikota, also detected the presence of a strong scattering layer in $73.5-77.5 \mathrm{~km}$ region from which radar echoes corresponding to $3 \mathrm{~m}$ irregularities were received. Based on the region of occurrence of irregularities, which was highly collisional, presence of significant shears in zonal and meridional components of wind measured by the chaff experiment, 10 min periodicity in zonal and meridional winds obtained by the MST radar and the nature of wave number spectra of the irregularities, it is suggested that the observed irregularities were produced through the neutral turbulence mechanism. The percentage amplitude of fluctuations across the entire scale size range showed that the strength of turbulence was stronger in the lower altitude regions and decreased with increasing altitude. It was also found that the amplitude of fluctuations was large in regions of steeper electron density gradients. MST radar observations showed that at smaller scales of turbulence such as $3 \mathrm{~m}$, (a) the thickness of the turbulent layer was between 2 and $3 \mathrm{~km}$ and (b) and fine structures, with layer thicknesses of about a $\mathrm{km}$ or less were also embedded in these layers. Rocket also detected 3-m fluctuations, which were very strong (a few percent) in lower altitudes $(67.5$ to $71.0 \mathrm{~km})$
\end{abstract}

Correspondence to: $\mathrm{H}$. Chandra

(hchandra@prl.res.in) and small but clearly well above the noise floor at higher altitudes. Rocket and radar results also point to the possibility of existence of thin layers of turbulence $(<450 \mathrm{~m})$. The turbulence parameters estimated from rocket-borne measurements of electron density fluctuations are consistent with those determined from MST radar observed Doppler spectra and the earlier works.

Keywords. Ionosphere (Ionosphere-atmosphere interactions; Ionospheric irregularities) - Meteorology and atmospheric dynamics (Turbulence)

\section{Introduction}

It is known that dynamical and convective instabilities contribute significantly to the dissipation of large-scale motions and the generation of turbulence in the middle atmosphere. The atmospheric gravity waves, which attain saturation amplitudes in the mesosphere, play a dominant role in the generation of instabilities leading to generation of turbulence. The dissipation of gravity waves and tides occurs due to cascade of wave energy to smaller scales via wave-mean flow and non-linear wave-wave interactions. As the gravity waves carry significant amount of momentum/heat fluxes, process of their breaking and resulting generation of turbulence is important for understanding the energetics and dynamics of the middle atmosphere. Larger scales of turbulent motion draw energy from the mean flow, and then a cascade of energy transfer to smaller scales takes place in the inertial sub-range and dissipation of smaller scale occurs due to viscous forces. In the mesosphere, the ion-neutral and electron-neutral collision frequencies are much higher than ion and electron gyrofrequencies, respectively and hence any perturbations produced in neutral density as a result of turbulence will also

Published by Copernicus Publications on behalf of the European Geosciences Union. 
be transmitted to ion and electron densities as well (Fritts, 1984). This aspect is utilized in all rocket-borne electron and ion density measurements as well as in the MST radar technique to derive neutral turbulence parameters.

Sinha (1976) and Prakash et al. (1980) detected smallscale electron density irregularities in $60-85 \mathrm{~km}$ altitude region from rocket-borne Langmuir probe (LP) measurements over the equatorial station Thumba $\left(8.5^{\circ} \mathrm{N}, 77^{\circ} \mathrm{E}\right)$ and suggested neutral air turbulence to be the generating mechanism. Thrane and Grandal (1981) and Thrane et al. (1985, 1987) derived neutral turbulence parameters from positive ion density measured by rocket-borne ion probes flown from a high latitude station Andoya $\left(69.3^{\circ} \mathrm{N}, 16^{\circ} \mathrm{E}\right)$. Chakrabarty et al. (1989) made ion density measurements from Thumba using spherical probe to study the turbulence. Sinha (1992) derived turbulence parameters in $60 \mathrm{~km} 82 \mathrm{~km}$ altitude region from a large number of rocket-borne electron density measurements conducted from Thumba. Lubken (1997) studied the seasonal variation of turbulence over high latitudes from measurements of neutral density fluctuations and found that the energy dissipation rates were low $\left(10-20 \mathrm{mWKg}^{-1}\right)$ during the winter and high $\left(\sim 150 \mathrm{mWKg}^{-1}\right)$ during summer. However, over the low latitude region, comparisons of simultaneous radar and rocket measurements are limited (Royrvik and Smith, 1984). Using the electron density irregularity data obtained from earlier sounding rocket flights from Sriharikota, and $3 \mathrm{~m}$ irregularity data obtained by the MST radar at Gadanki, which is located about $100 \mathrm{~km}$ west of Sriharikota, Chakravarty et al. (2004) showed that the fine structures in the electron density irregularities are often present in the height region of $\sim 75 \mathrm{~km}$ over Sriharikota, which match quite well with the radar observed structures of the main scattering layer $(70 \pm 5 \mathrm{~km})$ over Gadanki.

Using the MST radar of the National Atmospheric Research Laboratory (NARL) at Gadanki, a series of experiments were conducted to study the low-latitude mesospheric winds and turbulence. Datta et al. (2001) and Sasi et al. (2001) reported preliminary results on the variability of mesospheric backscattered echoes and associated features of turbulence. The details of characteristic morphological variations of the mesospheric backscattered echoes over Indian and other global stations (Gage and Balsley, 1980; Kubo et al., 1997; Kamala et al., 2003; Kumar et al., 2007) may be summarized as follows: (a) The radar backscattered signals from the mesosphere are generally intermittent with high spatial variability barring exceptions of Polar Mesosphere Summer Echoes (PMSEs) (b) There are at least 2 narrow height regions in the mesosphere viz., $72-77 \mathrm{~km}$ and 80 $85 \mathrm{~km}$, which produce relatively strong radar backscatter on a more regular basis. The peak heights of the regions also vary with latitude and season. Over the high latitudes, strong PMSEs are obtained from $82-85 \mathrm{~km}$ height range but during other seasons significant but weak backscatter echoes are generated from lower height regions $(<80 \mathrm{~km})$ also, (c) Over the low latitude stations e.g. Jicamarca and Gadanki, the main scattering layer lies around $\sim 75 \pm 5 \mathrm{~km}$ with another weak region of radar scattering around $80 \pm 5 \mathrm{~km}$; the $75 \pm 5 \mathrm{~km}$ scattering region showing seasonal dependence with the strongest echo seen during June/July months and the weakest during winter.

Royrvik and Smith (1984) investigated equatorial mesosphere using both the Jicamarca VHF radar and rocketborne LP measurements during the CONDOR campaign of February-March 1983. The two sites were separated by about $60 \mathrm{~km}$ along N-S. Narrow layer of radar echoes was seen at $79 \mathrm{~km}$ (radar resolution of $3 \mathrm{~km}$ ) $1 \mathrm{~h}$ before the rocket launch but moved to range gates of 79 and $82 \mathrm{~km}$ at the time of rocket launch. The Langmuir probe detected irregularities in a narrow altitude region $(85.2-86.6 \mathrm{~km})$. It was inferred that the same scattering layer was observed by the two techniques. Simultaneous rocket-borne measurements of electron and ion densities and MST radar observations were also made from Poker Flat during the Middle Atmosphere Program (MAP) (Goldberg et al., 1988; Blood et al., 1988) to study the neutral turbulence. Rocket-borne measurements were also made from Alcantara $\left(2.5^{\circ} \mathrm{S}, 44.4^{\circ} \mathrm{W}\right)$ in Brazil, but no simultaneous radar measurements were made (Goldberg et al., 1997).

In this paper, the first campaign results based on coordinated observations of electron density with in-situ rocket probes and mesospheric echoes using MST radar are presented. These observations are first of its kind from low latitude region in the Indian sector. Mesospheric turbulence parameters studied using the two techniques are compared and their generation processes are discussed.

\section{Experimental details}

A RH-300 Mk II rocket carrying a Langmuir probe (LP) payload and an RH-200 rocket carrying metallic chaff payload were launched on 23 July 2004 at 11:42 LT and 12:15 LT, respectively, from Sriharikota in coordination with the MST radar observations made from Gadanki. Launch criterion was decided based on the mesospheric echo strength observed in the MST radar observations. The rocket nose cone ejection was at $60 \mathrm{~km}$ and the rocket reached an apogee of $109 \mathrm{~km}$. Figure 1 shows the location of Gadanki (MST radar), Sriharikota (rocket launch site) and the trajectory of the RH-300 Mk II rocket.

A fixed bias LP, similar to the one described by Prakash and Subbaraya (1967) was used to measure electron density fluctuations. LP sensor was mounted on the top deck of the RH 300 MK II rocket. The LP senor was a split sphere (50 $\mathrm{mm}$ diameter), whose upper hemisphere was biased at $+4 \mathrm{~V}$ and was used to collect the electron current, and the lower hemisphere was used as a guard electrode. The LP sensor was mounted with the help of a $200 \mathrm{~mm}$ long boom. The electrical connection to the signal conditioning electronics was provided by means of a coaxial cable. The electronics 


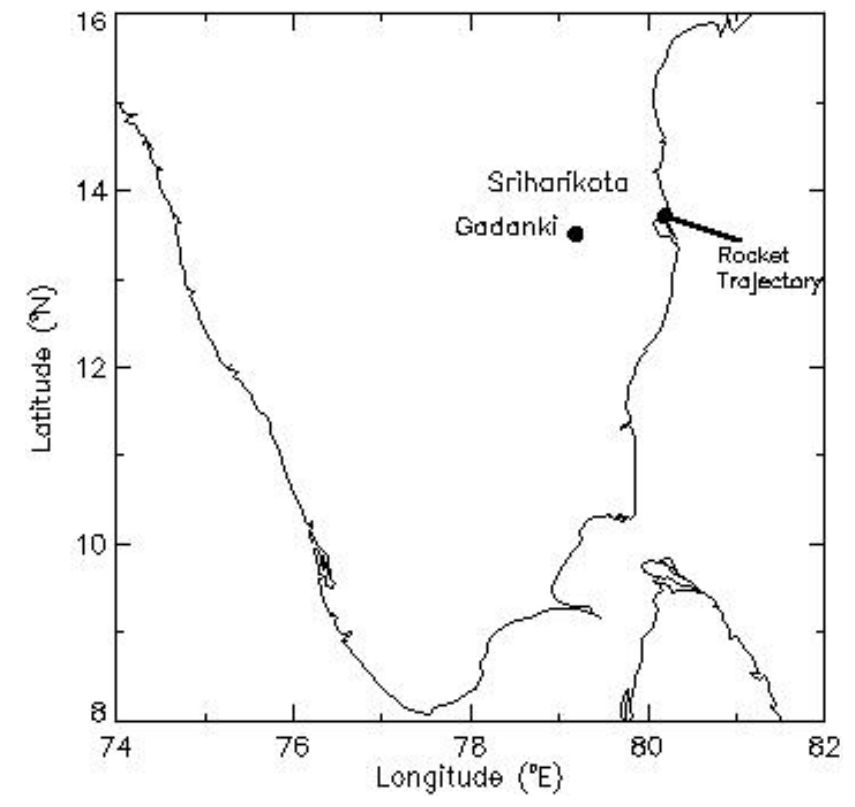

Fig. 1. Map showing the location of Indian MST radar at Gadanki and the rocket range at Sriharikota. The trajectory of the rocket is also marked.

was accommodated in a package mounted on one of the instrument decks. To cover the large dynamical range arising from the change in current due to variation in the electron density an automatic gain amplifier was used to measure the current in the range of $1 \mathrm{nA}$ to about $3 \mu \mathrm{A}$. For studying the electron density fluctuations in different scale sizes the current collected by the LP sensor was processed on board in three channels with different gains having frequency response of $0-100 \mathrm{~Hz}, 30-150 \mathrm{~Hz}$ and $70-1000 \mathrm{~Hz}$. These channels are named as LP Main, LP MF and LP HF, respectively and were sampled at $520 \mathrm{~Hz}, 1040 \mathrm{~Hz}$ and $5200 \mathrm{~Hz}$, respectively. The consolidated wave number power spectra of irregularities were constructed from the electron density values obtained from these three channels. The normalization of MF and Main and MF and HF channels was done at $50 \mathrm{~Hz}$ and $100 \mathrm{~Hz}$, respectively. With a typical rocket velocity of $1000 \mathrm{~ms}^{-1}$, in the region of interest, the spectrum, therefore, gives information about the irregularities having scale sizes in the range of approximately $1 \mathrm{~m}$ to $1 \mathrm{~km}$. FFT was used to estimate the power spectra and a Hanning window used for smoothing to avoid leakage at higher frequencies. In addition, FFT of LP Main channel data were computed every 1024 points (which corresponds to approximately data of $1 \mathrm{~km}$ vertical extent) to construct a sonogram, which provides a bird's eye view of significant frequencies/scale sizes present at different altitudes. One RH-200 meteorological rocket with chaff payload was launched at 12:15 LT, i.e., after about half an hour of the launch of RH-300 Mk II. The metallic chaffs were tracked by radars, which provided zonal and meridional wind profiles in the height range of $20-76 \mathrm{~km}$.

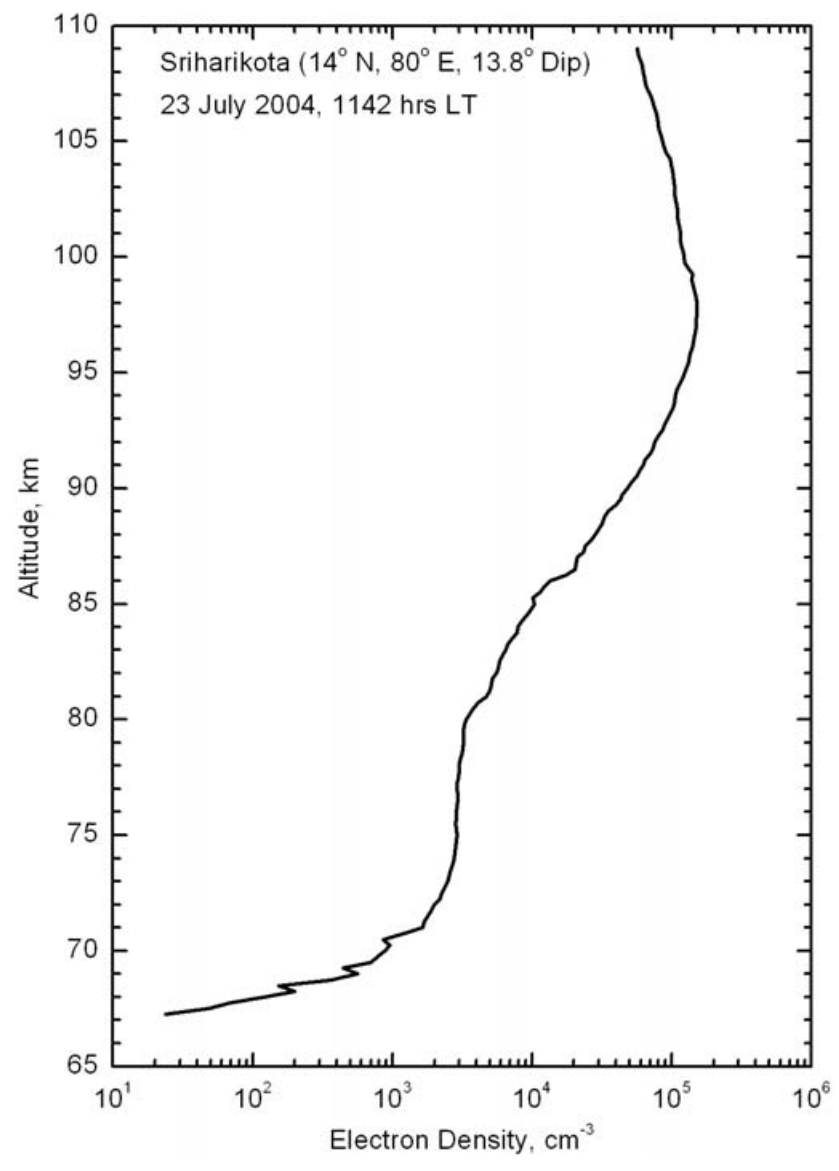

Fig. 2. Electron density profile during ascent of the rocket from the fixed bias Langmuir probe flown on RH-300 Mk II rocket launched from Sriharikota.

The MST radar of the National Atmospheric Research Laboratory (NARL) is located at Gadanki and operates at $53 \mathrm{MHz}$ (Rao et al., 1995). For the present campaign the month of July was chosen based on the earlier studies of mesospheric echoes from Gadanki as the occurrence and the strength of echoes were found to be highest during JuneJuly (Kamala et al., 2003). On 23 July 2004 the MST radar was operated during 08:30-16:00 LT. Detailed experimental parameters used for the radar operation are presented in Table 1 . Uncoded $3 \mu$ s pulses were used to provide a height resolution of $450 \mathrm{~m}$ during the rocket launch period. Five radar beam directions (north- $10^{\circ}$, south- $10^{\circ}$, east- $10^{\circ}$, west$10^{\circ}$ and zenith) were used to get return echoes from $60 \mathrm{~km}$ to $120 \mathrm{~km}$. The angles refer to zenith angles used for the experiments. As seen by the ground-based magnetometers located at Tirunelveli $\left(8.7^{\circ} \mathrm{N}, 77.8^{\circ} \mathrm{E}\right)$ and Alibag $\left(18.6^{\circ} \mathrm{N}\right.$, $\left.72.9^{\circ} \mathrm{E}\right)$, the rocket was launched during a magnetically disturbed day $\left(A_{p}=52\right)$.

The rocket data gives relative amplitude of electron density fluctuations for vertical scale sizes ranging from a few $\mathrm{km}$ down to a few meters. But in view of steep spectra of 
Table 1. Specifications of the radar operating parameters.

\begin{tabular}{ll}
\hline Parameter & Specifications \\
\hline Location & Gadanki $\left(13.5^{\circ} \mathrm{N}, 79.2^{\circ} \mathrm{E}\right)$ \\
Frequency & $53 \mathrm{MHz}$ \\
Peak power aperture product & $3 \times 10^{10} \mathrm{~W} \mathrm{~m}^{2}$ \\
Peak power & $2.5 \mathrm{MW}$ \\
Maximum duty ratio & $2.5 \%$ \\
Number of Yagi antennas & 1024 \\
Beam width (3 dB full width) & $3^{\circ}$ \\
Beam angle & zenith and $10^{\circ}$ off zenith \\
Number of Beams used & East, West, Zenith, North, South \\
Pulse width & $3 \mu \mathrm{s}$ uncoded $(450 \mathrm{~m})$ \\
Inter Pulse Period & $0.9 \mathrm{~ms}$ \\
Maximum number of range bins & 125 \\
Number of Coherent integrations & 40 \\
Maximum number of FFT points & 256 \\
\hline
\end{tabular}

fluctuations in the viscous dissipation regime $(n=-7)$, rocket cannot detect weak fluctuations at meter scales in regions of low electron density. In some of the cases the scales of turbulence in viscous dissipation regime is much smaller than the detection limit of rocket. The MST radar on the other hand can detect $3 \mathrm{~m}$ fluctuations even when they are extremely weak. Also, due to different locations of rocket range and the radar site, it was not possible to look at the same volume by both techniques. Another problem is the inability of the Chaff technique to provide winds above about $75 \mathrm{~km}$ altitude. Although these shortcomings of the experimental data set do not allow us to draw firm conclusions, a number of interesting results and properties of mesospheric turbulence are reported in this paper.

\section{Results}

\subsection{Electron density fluctuations from Langmuir probe}

Figure 2 shows the electron density profile obtained during the ascent of the rocket. During the down leg, the rocket appeared to be tumbling below $90 \mathrm{~km}$ so the results for descent are not considered. A small spin modulation at $4.6 \mathrm{~Hz}$ was present through out the flight. The current collected by the LP sensor was converted into electron density by calibrating the maximum electron density of E-region obtained by the rocket with the electron density determined from the critical frequency of E-layer obtained from an ionosonde at Sriharikota. During the rocket ascent, steep gradients of electron density were observed between 67.5 and $71 \mathrm{~km}$ but beyond this height, such sharp gradients were generally absent and the profile showed a relatively slow and monotonic increase of electron density. Figure 3 shows the electron density gradient scale length, $L\left[1 / L=\left(1 / n_{e}\right)\left(d n_{e} / d h\right)\right]$ calculated over an altitude interval of $200 \mathrm{~m}$. It can be seen that very strong positive and negative gradients were present

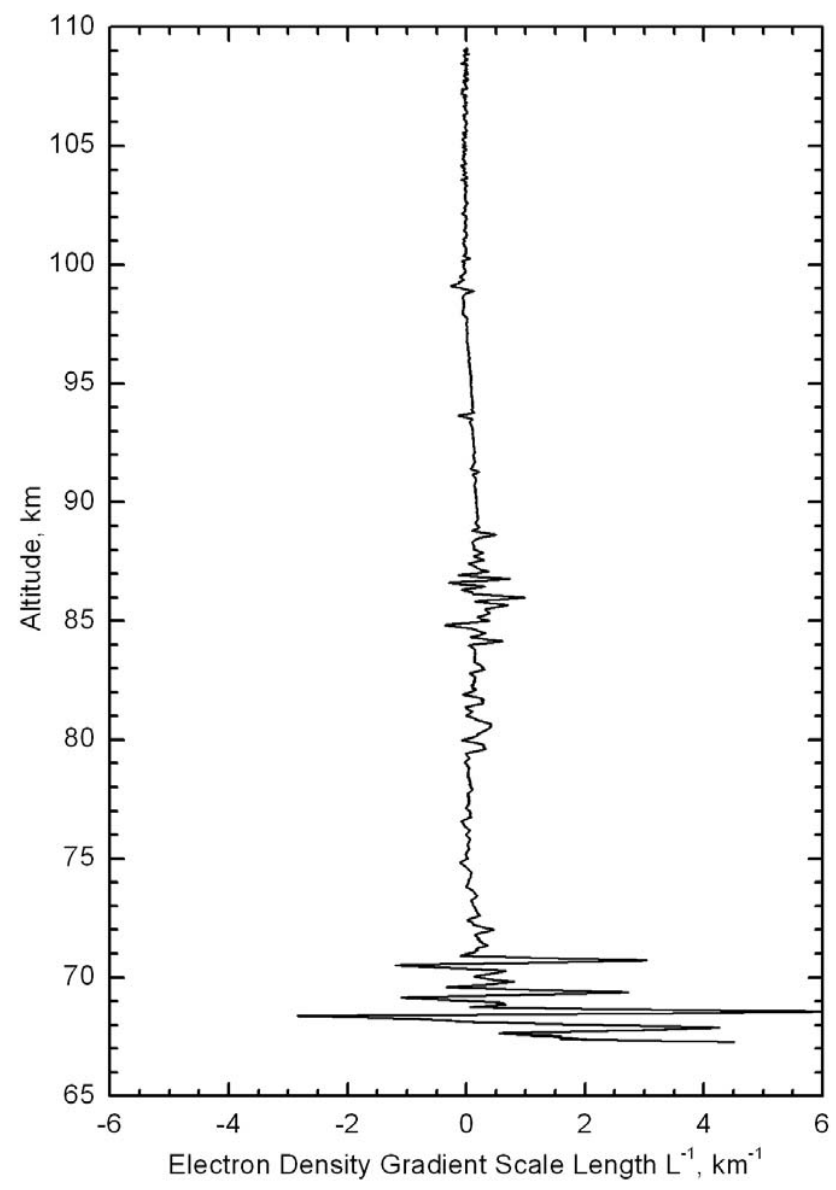

Fig. 3. Electron density gradient scale length, $L^{-1}$ over $200 \mathrm{~m}$ during the ascent of the RH 300 MK II rocket launched at 11:42 LT from Sriharikota on 23 July 2004.

in $67.5-71 \mathrm{~km}$ region, moderate gradients in the $84-89 \mathrm{~km}$ region and weak gradients in the intervening region (71$85 \mathrm{~km})$.

Figure 4 shows power spectra of fluctuations constructed from the rocket data of all the three channels mentioned above, for altitude ranges of $67.5-69.3 \mathrm{~km}, 69.3-$ $71.0 \mathrm{~km}, 74.9-76.5 \mathrm{~km}, 76.5-78.0 \mathrm{~km}, 84.0-86.6 \mathrm{~km}$ and $86.6-89.0 \mathrm{~km}$, which will henceforth be termed as R1, R2, R3, R4, R5 and R6 regions. The spectra in all the six ranges were estimated using 1024 points, which corresponds to about $4 \mathrm{~s}$ data for R1 and R2, about $6 \mathrm{~s}$ data for R3 and R4 and about $8 \mathrm{~s}$ data for R5 and R6 regions. Scale sizes $(\lambda)$ corresponding to different wave numbers $(k)(\lambda=2 \pi / k)$ are marked on the top of the Fig. 4.

A model given by Heisenberg (1948), which exhibits a smooth transition between the inertial sub range (ISR) and the viscous dissipation regime (VDR) with spectral indices of $-5 / 3$ and -7 , respectively, is well accepted in the literature to replicate the turbulence spectrum. This model was fitted to four spectra for the altitude regions R3 to R6, which indicates 


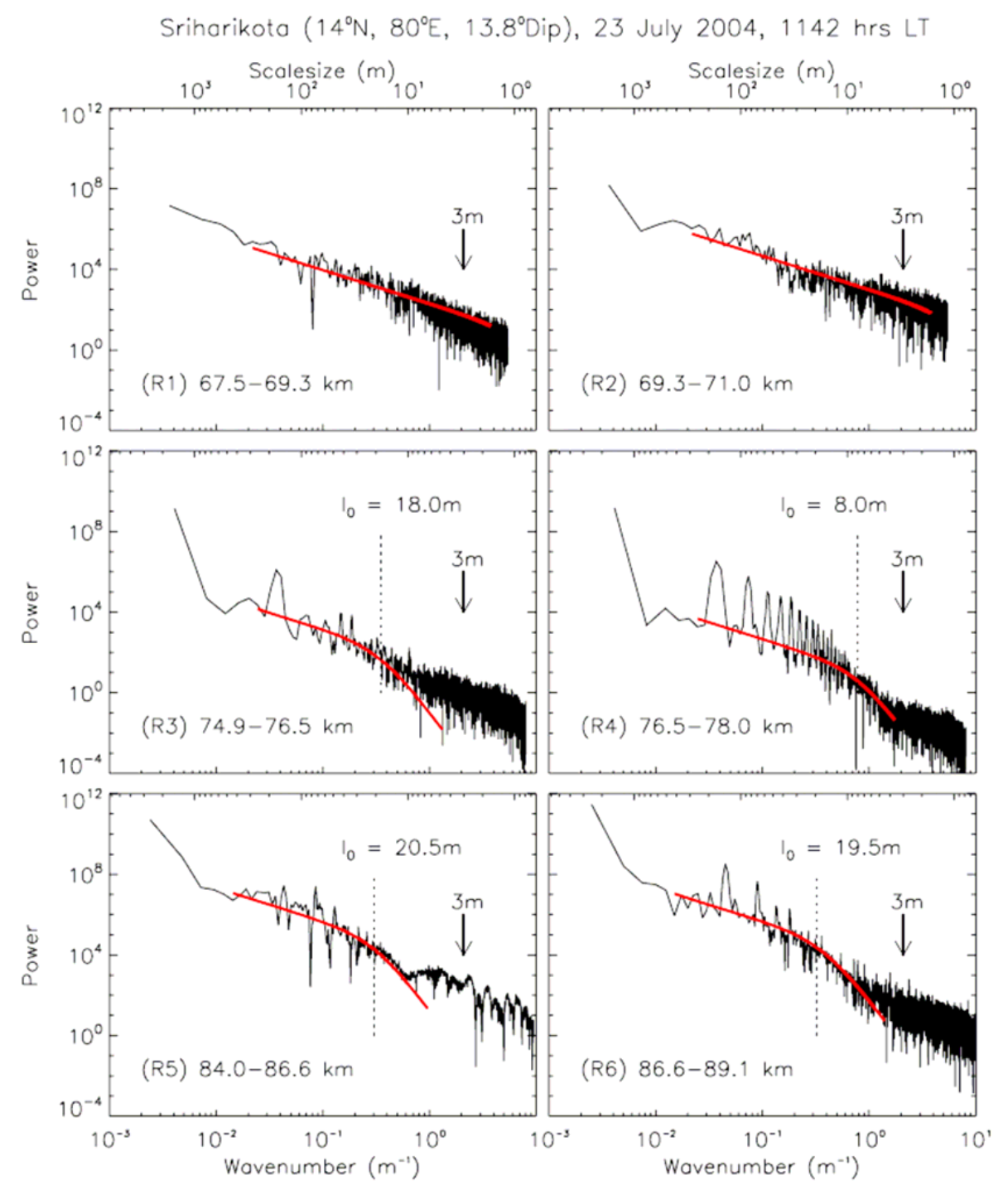

Fig. 4. Spectra of electron density irregularities in $67.5-69.3 \mathrm{~km}, 69.3-71 \mathrm{~km}, 74.9-76.5 \mathrm{~km}, 76.5-78.0 \mathrm{~km}, 84-86.6 \mathrm{~km}$ and $84-89 \mathrm{~km}$ regions computed from Langmuir probe measurements. The solid line is the Heisenberg model fitted to the spectrum. The inner scale of turbulence $l_{0}$ obtained from model fit is also shown wherever it can be determined. The arrow points towards wave numbers corresponding to $3 \mathrm{~m}$ scale size.

the presence of turbulence in these regions (Fig. 4). The best fit of the Heisenberg model to the power spectra identifies the break point between the ISR and the VDR, which occurs at a wave number corresponding to the inner scale of turbulence $\left(l_{0}\right)$. For regions R3, R4, R5 and R6, the inner scales identified are 18.0, 8.0, 20.5 and $19.5 \mathrm{~m}$, respectively.

For the R5 region, the Heisenberg's model could be fitted only up to $10 \mathrm{~m}$ scale and the inner scale was found to be about $20.5 \mathrm{~m}$. Thus one can say that the fluctuations from large scales down to $10 \mathrm{~m}$ scale size were due to the neutral turbulence. At scales lower than $10 \mathrm{~m}$, where there was significantly larger power, the spectrum indicates that the source of these fluctuations was not neutral turbulence. Plasma instabilities such as cross-field instability could be responsi- ble for these small-scale irregularities and such irregularities have been reported earlier in this altitude region during the daytime (Prakash et al., 1971). Sinha and Prakash (1987) have reviewed the rocket observations of E-region irregularities produced through the cross-field instability.

For the altitude ranges R1 and R2, the model could not be fitted as the spectral indices of the entire scale size range observed by the LP was $-5 / 3$ (Fig. 4), which is typical of the ISR. The scales in the VDR at these altitudes were beyond the detection limit of the instrument and hence the inner scale could not be identified. However, as the slopes of spectra were $-5 / 3$, it indicates the presence of ISR and hence the presence of turbulence at these altitudes also. 


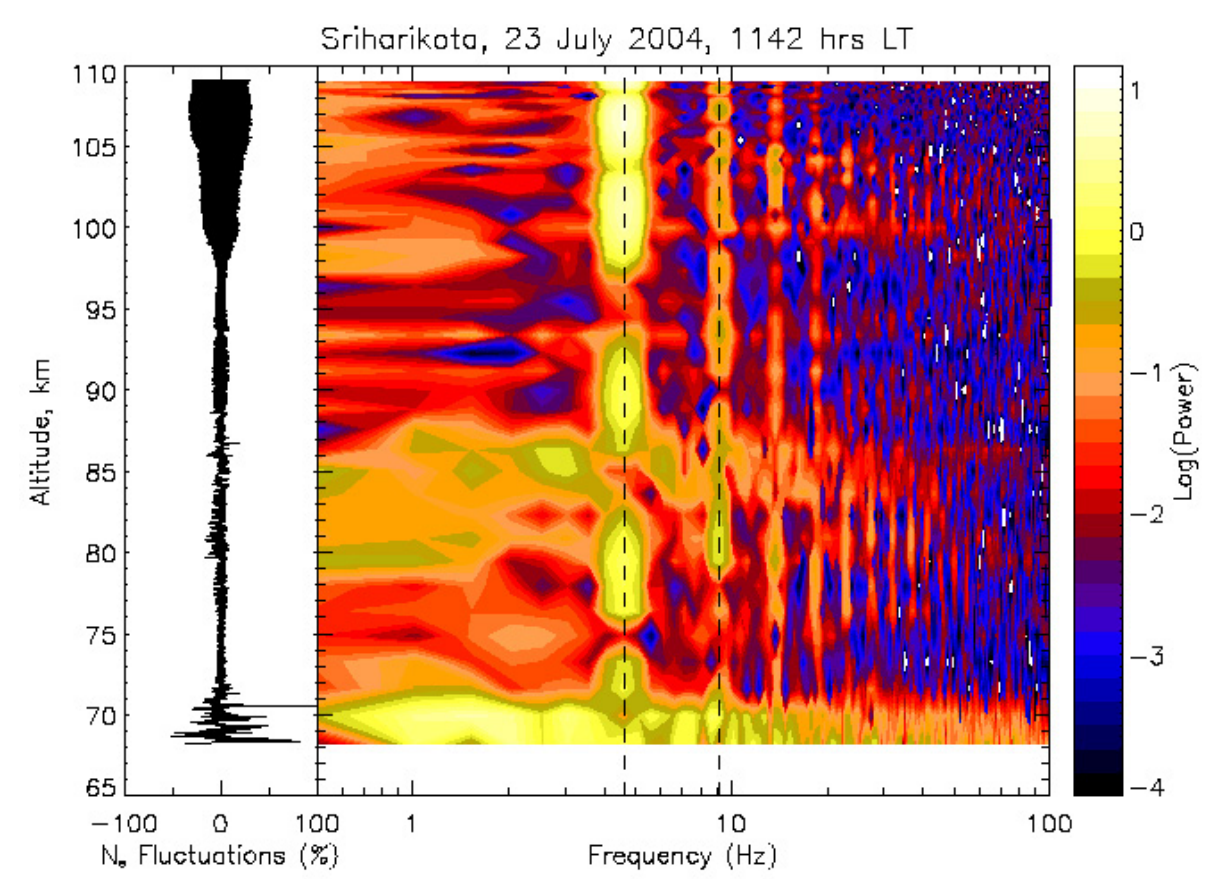

Fig. 5. A sonogram showing the strength of irregularities of different frequencies with altitude. Two vertical black dashed lines are the fundamental and the second harmonic of the rocket spin frequency. The vertical panel on the left shows the relative strength of electron density fluctuations as seen in the LP Main channel.

As shown in Fig. 4, 3-m fluctuations in R1 and R2 regions fall in the ISR and for R3 to R6 ranges in the VDR. It can be seen very clearly that the $3-\mathrm{m}$ fluctuations are quite strong and well above the noise floor for R1 and R2 regions and slightly above the noise floor for the R6 region.

Table 2 shows the percentage amplitude of the fluctuations in electron density for a few scale sizes lying in $3 \mathrm{~m}-50 \mathrm{~m}$ in all the six altitude regions computed from the spectra shown in Fig. 4. It can be seen that the percentage amplitudes of irregularities with scale sizes range of $3 \mathrm{~m}-50 \mathrm{~m}$, which fall mostly within the inertial sub-range and partly in the VDR, are much higher in the lower altitude region as compared to the upper regions. The percentage amplitude of fluctuations decreases with the decrease of scale size. The percentage amplitude of 3-m fluctuations was $2.4 \%, 1.6 \%$ and $0.03 \%$ in R1, R2 and R6 regions, respectively. For regions R3 and R4, the percentage amplitudes of $3 \mathrm{~m}$ fluctuations were below the sensitivity of the LP.

Figure 5 shows a sonogram constructed from the data of the LP Main channel which shows the presence of irregularities of having frequencies (scale sizes) up to $100 \mathrm{~Hz}$ (greater than about $10 \mathrm{~m}$ ) at different altitudes. The rocket spin frequency and its second harmonic can be seen very clearly in the sonogram. The sonogram also shows that the irregularities are present in the entire altitude region of 67.5 to $89 \mathrm{~km}$, though with varying amplitudes. The strongest irregularities are present in $67.5-71 \mathrm{~km}$ and $84-89 \mathrm{~km}$ regions.

\subsection{Horizontal winds from chaff release}

Figure 6 shows the zonal and meridional components of the neutral wind derived from radar tracking of metallic chaff released by the RH-200 rocket launched at 12:15 LT on 23 July 2004. Zonal component of the wind was predominantly westwards for the entire height range except that it became eastwards above about $74 \mathrm{~km}$. This shows that strong shears in zonal winds were present between 73 and $76 \mathrm{~km}$. As shown in Fig. 6, moderate shears in the meridional component of the wind were also present in $70-76 \mathrm{~km}$ altitude range, establishing that the horizontal wind in the height range of $70-76 \mathrm{~km}$ had shears of about $20 \mathrm{~ms}^{-1} \mathrm{~km}^{-1}$. Because of inherent limitation of this rocket-chaff technique, it was not possible to measure wind velocities beyond the height range of 75-76 km (Chakravarty et al., 1992).

\subsection{Radar observations}

\subsubsection{Mesospheric echoes and variabilities}

Figure 7 shows height-time intensity (HTI) diagram of mesospheric echoes observed on 23 July 2004 for all scans taken together at different beam positions. Top panel shows the HTI diagram during 09:00-16:00 LT and the bottom panel shows the amplified view of the same diagram during 09:0010:30 LT to show the presence of the layer in $65-67 \mathrm{~km}$ region. Echo SNR is represented in logarithmic scale as shown on the right side of Fig. 7. It may be mentioned that 
Table 2. Percentage amplitude of irregularities produced by the neutral turbulence mechanism in six altitude regions.

\begin{tabular}{ccccccc}
\hline \multirow{2}{*}{ Scale size $(\mathrm{m})$} & \multicolumn{5}{c}{ Percentage amplitude $(\%)$} \\
& $67.5-69.3 \mathrm{~km}$ & $69.3-71.0 \mathrm{~km}$ & $74.9-76.5 \mathrm{~km}$ & $76.5-78.0 \mathrm{~km}$ & $84.0-86.6 \mathrm{~km}$ & $86.6-89.0 \mathrm{~km}$ \\
\hline 3 & 2.4 & 1.6 & $*$ & $*$ & $*$ & 0.03 \\
5 & 3.4 & 3.0 & $*$ & $*$ & $*$ & 0.04 \\
10 & 9.6 & 4.9 & 0.2 & $*$ & 1.1 & 0.10 \\
20 & 19.5 & 8.5 & 0.4 & 3.0 & 1.6 & 0.45 \\
30 & 25.3 & 10.2 & 1.2 & 3.9 & 4.0 & 2.13 \\
40 & 33.8 & 16.8 & 1.3 & 7.0 & 5.8 & 5.50 \\
50 & 43.3 & 28.5 & 1.6 & & & $*$ \\
\hline
\end{tabular}

* These amplitudes were below the detection limit of LP

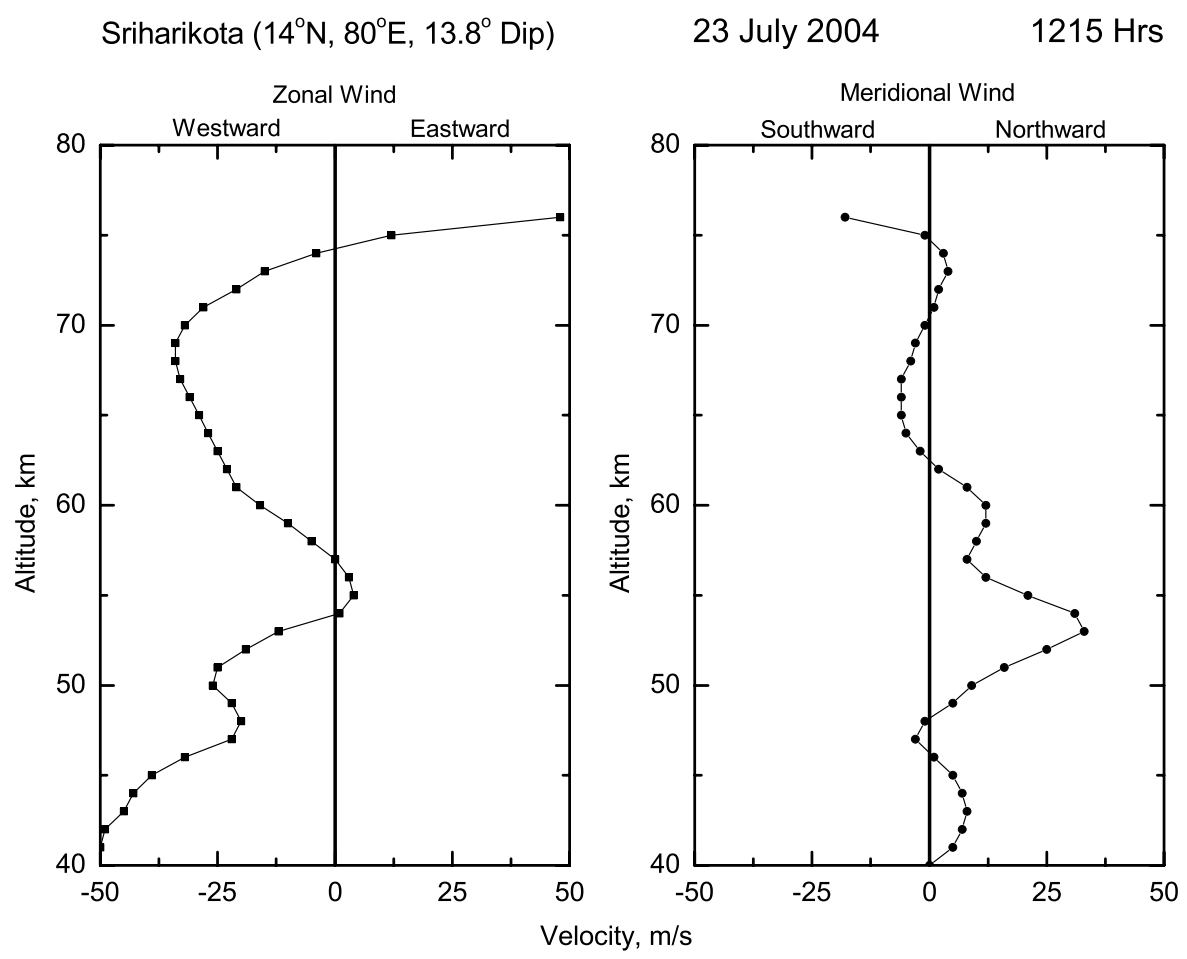

Fig. 6. Zonal and meridional wind profiles obtained from radar tracking of metallic chaff released from a RH 200 rocket launched from Sriharikota.

SNR computation has been done with noise power reckoned over the coherent integration filter bandwidth of $27.7 \mathrm{~Hz}$. Since the signal bandwidth is typically $2 \mathrm{~Hz}$ for the mesospheric echoes observed by VHF radar and also the echoes are weak due to weak refractive index fluctuations/gradients, SNR generally is found to be less than 1 . In the present observational scheme, mean noise floor in terms of SNR is $-18 \mathrm{~dB}$ and SNR of random noisy peak (which has no time and height continuity) is about $-12 \mathrm{~dB}$. Thus any signal stronger than $-12 \mathrm{~dB}$ should be considered as reliable mesospheric echoes. Maximum SNR is found to $6 \mathrm{~dB}$, which means the mesospheric echoes had a dynamic range of $18 \mathrm{~dB}$
$(-12 \mathrm{~dB}$ to $6 \mathrm{~dB})$ and the strongest signal is $18 \mathrm{~dB}$ higher than noise. The vertical distribution of radar backscattered signals shows the presence of a strong scattering layer in 73.5-77.5 km region during 10:45 and 13:15 LT, a scattering layer in 68-70 km region around 13:25 h and another scattering layer around 65-67 km region during 09:00-10:30 LT.

To present the height time variabilities of the echoes in different beam directions, SNRs observed in different beams are shown separately in Fig. 8 for the period 10:40-12:30 LT. As evident from these figures, echoes were observed more times in east, west and zenith beams as compared to north and south beams. It may also be noted that in general echoes 

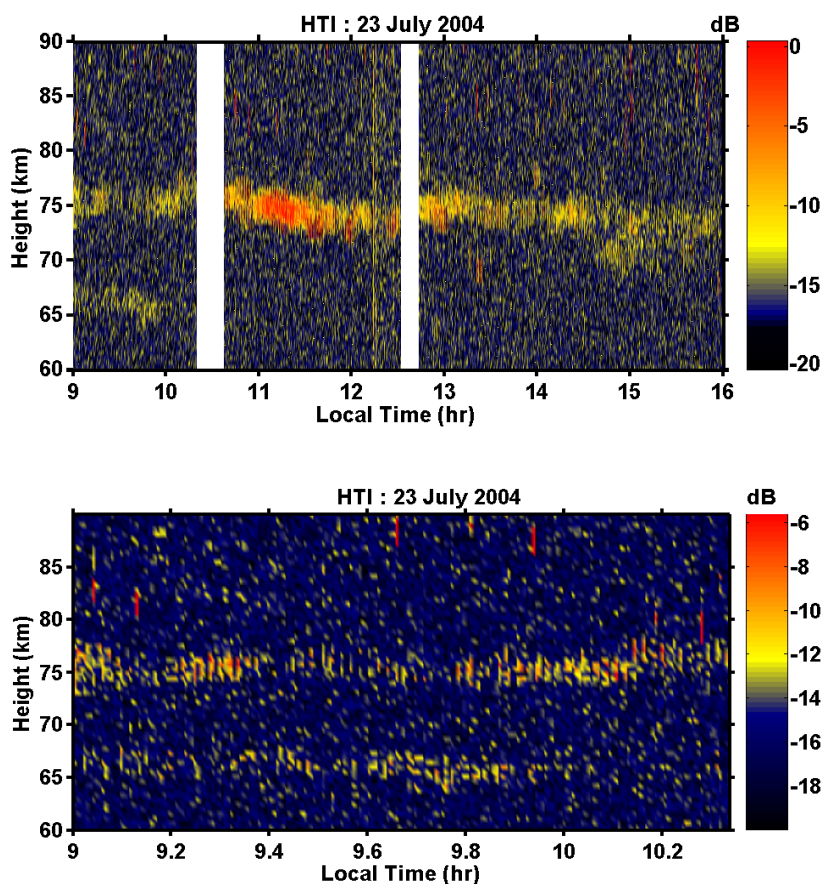

Fig. 7. Height Time Intensity (HTI) diagram constructed from the MST radar echoes at Gadanki, with $450 \mathrm{~m}$ altitude resolution. The top panel shows the strength of radar echoes during 09:00-16:00 LT and the bottom panel shows the amplified view of echoes during 09:00-10:30 LT. Scales on the right shows the echo SNR.

are weaker in the east and south beam as compared to west, zenith and south beams.

\subsubsection{Horizontal winds derived using MST radar observa- tions}

Figure $9 \mathrm{a}$ and $\mathrm{b}$ shows zonal and meridional components of the winds derived using the MST radar observations shown in Fig. 8. Positive (negative) velocity represents eastward/northward (westward/southward) winds. It can be seen that both zonal and meridional winds are mostly within $\pm 20 \mathrm{~ms}^{-1}$ and are in good agreement with those observed by the rocket-borne chaff experiment (Fig. 6). The time variation of the zonal and meridional wind components averaged within the altitude region of the scattering layer $(75-77 \mathrm{~km})$ is shown in Fig. 10. The magnitude of the zonal winds, which are mostly westward, varies between few $\mathrm{ms}^{-1}$ to $-40 \mathrm{~ms}^{-1}$ with most of the points between 0 and $-20 \mathrm{~ms}^{-1}$. A periodicity close to $10 \mathrm{~min}$ can be seen clearly in both the wind components. The meridional winds are mostly northward and their magnitude varies between 0 and $40 \mathrm{~ms}^{-1}$ with most of the points between 0 and $20 \mathrm{~ms}^{-1}$. To see the altitude variation of zonal and meridional winds, average winds for $7 \mathrm{~min}$ duration for an altitude range of 74-77 km for 11:42 LT and 11:57 LT have been shown in Fig. 11. The first time corresponds to the RH-300 rocket launch time and the other just

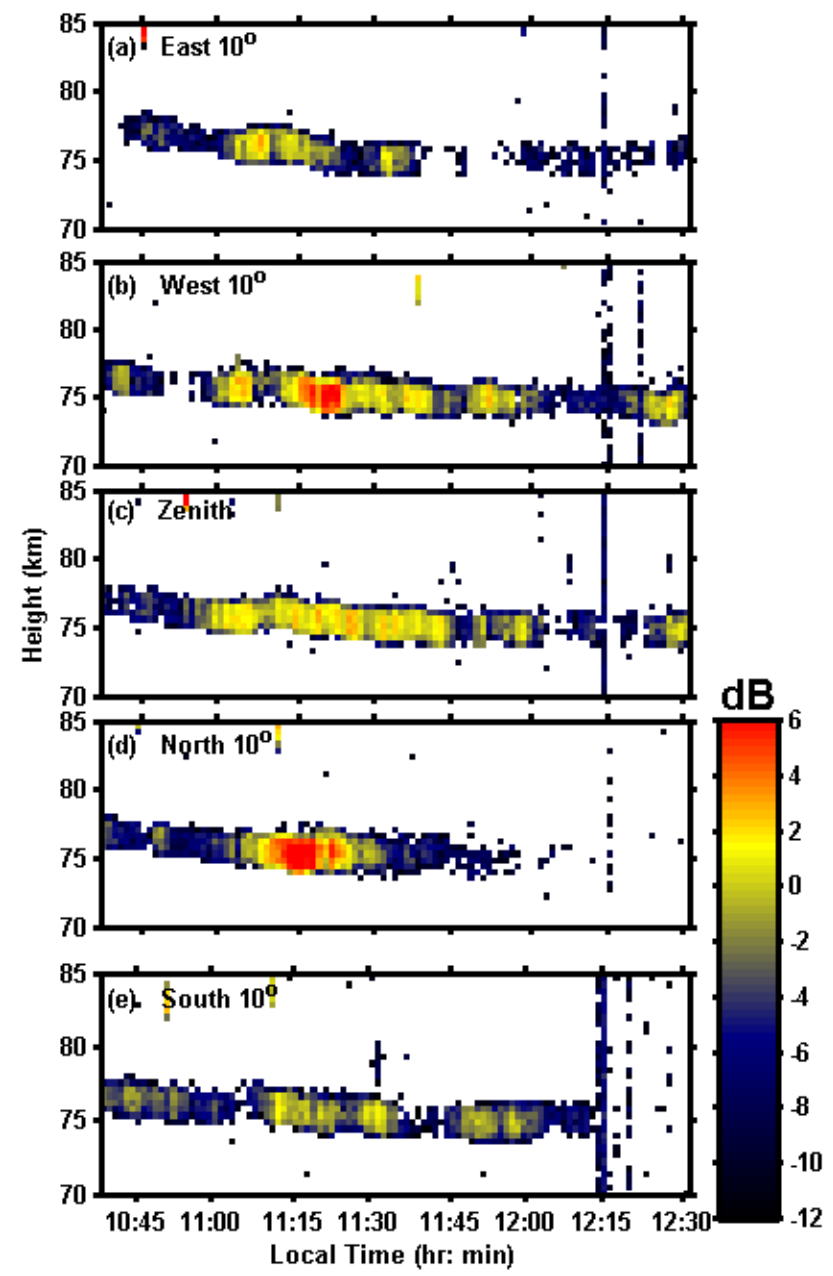

Fig. 8. Signal plots of the radar echoes along the five beams on 23 July 2004.

15 min after that. It would have been good to compute these wind components around 12:15 LT, which was the launch time of Chaff flight but the radar did not observe echoes in all the beams and hence the wind components could not be estimated correctly at 12:15 LT. At 11:42 LT the zonal velocity was in the range of -10 to $5 \mathrm{~ms}^{-1}$ and the meridional component in the range of 10 to $15 \mathrm{~ms}^{-1}$. At 11:57 LT, the zonal component was westward with values in the range of -10 to $-15 \mathrm{~ms}^{-1}$ and the meridional component was close to $15 \mathrm{~ms}^{-1}$ with one value at the top echoing region being about $5 \mathrm{~ms}^{-1}$. The two sets of profiles are quite consistent. Comparing with the chaff-derived velocities over SHAR, the basic pattern of winds appears similar in nature both in magnitude and direction. The periodicity of $10 \mathrm{~min}$ seen both in zonal and meridional components in $75-77 \mathrm{~km}$ region points towards the possibility of the presence of gravity waves and hence the turbulence. 

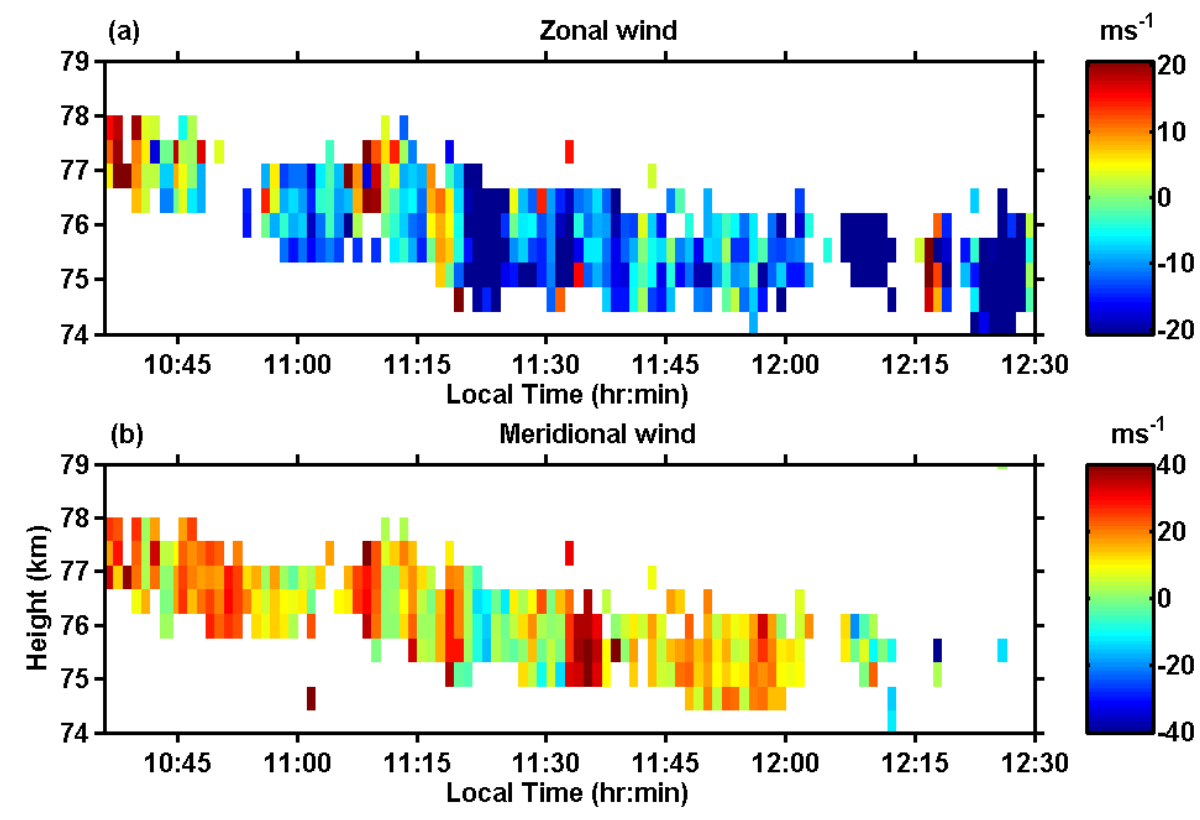

Fig. 9. Range-time-velocity maps showing (a) the zonal and (b) meridional wind components over Gadanki on 23 July 2004.
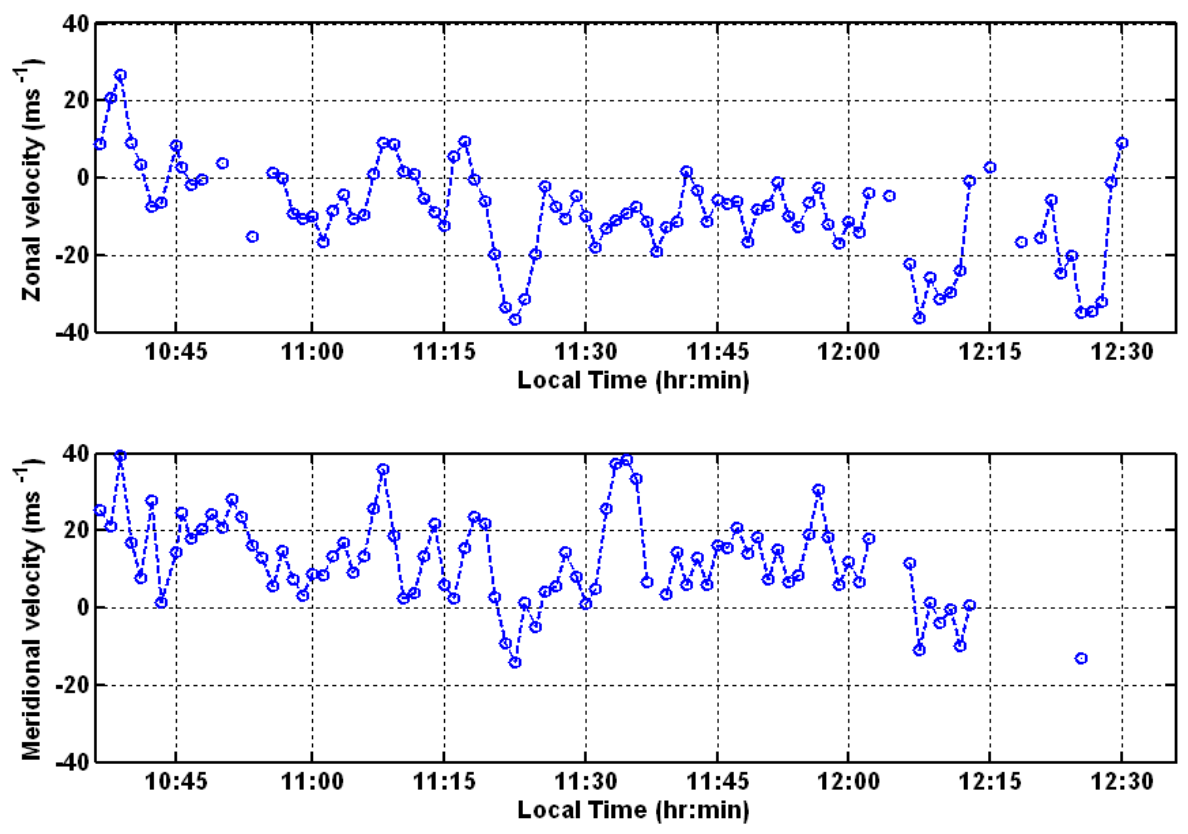

Fig. 10. Time variation of the zonal and meridional components of wind averaged over 75-77 km over Gadanki on 23 July 2004.

\subsubsection{Doppler spectral width}

Spectral widths observed in different beam directions are shown in Fig. 12. These represent mean and standard deviations of spectral widths observed in different directions. Spectral widths presented in zonal (meridional) direction have been obtained by combining observations made in east and west (north and south) beams. In these figures, spec- tral width represents square root of variance. In general the spectral widths vary between 1 and $3 \mathrm{~ms}^{-1}$ with most values between 2 and $3 \mathrm{~ms}^{-1}$. The values are found to be somewhat more in the east-west beams as compared to north-south beams as well as zenith. 
Table 3. Turbulence parameters obtained by rocket-borne LP.

\begin{tabular}{cccccc}
\hline Parameter & Units & $74.9-76.5 \mathrm{~km}$ & $76.5-78.0 \mathrm{~km}$ & $84.0-86.6 \mathrm{~km}$ & $86.6-89.0 \mathrm{~km}$ \\
\hline$l_{0}$ & $\mathrm{~m}$ & 18 & 8 & 20.5 & 19.5 \\
$\eta$ & $\mathrm{m}$ & 2.43 & 1.08 & 2.77 & 2.64 \\
$\varepsilon$ & $\mathrm{mWKg}^{-1}$ & 1 & 59 & 164 & 200 \\
$\mathrm{~K}$ & $\mathrm{~m}^{2} \mathrm{~s}^{-1}$ & 1.8 & 113 & 298 & 365 \\
$u_{z}$ & $\mathrm{~m}^{2} \mathrm{~s}^{-2}$ & 0.33 & 2.67 & 4.4. & 4.87 \\
$L_{B}$ & $\mathrm{~km}$ & 0.11 & 0.91 & 1.45 & 1.61 \\
\hline
\end{tabular}
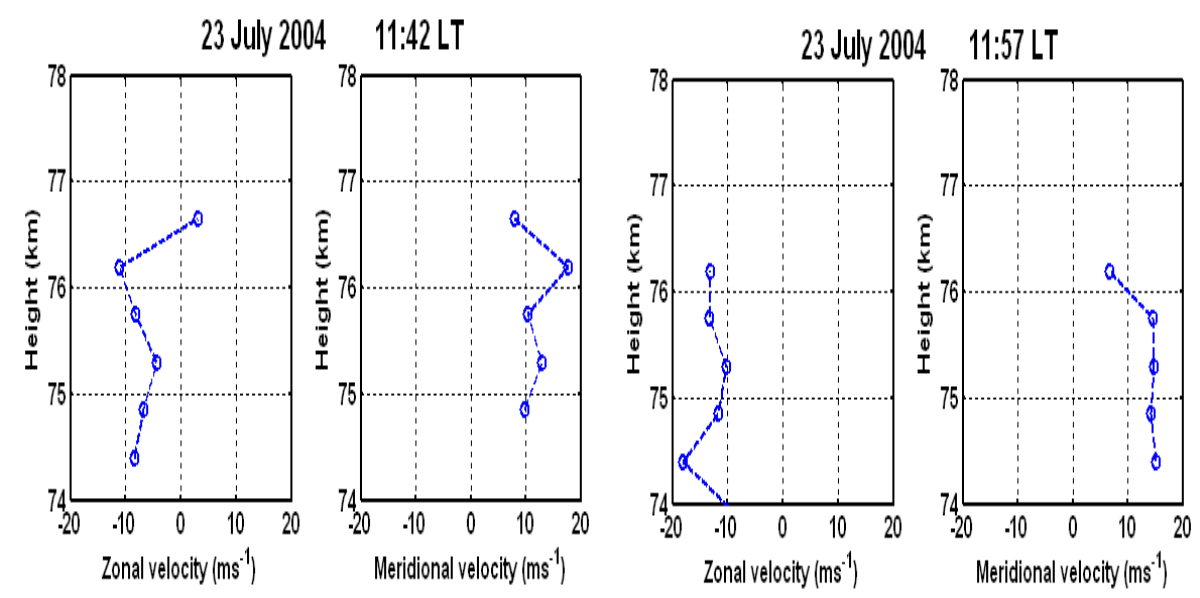

Fig. 11. Altitude variation of the zonal and meridional winds over Gadanki at the time of RH 300 rocket launch (11:42 LT) and at 11:57 LT, which is close to the time of RH 200 rocket launch on 23 July 2004.

\section{Turbulence parameters derived using rocket and radar observations}

\subsection{Rocket observations}

Turbulence parameters are derived from power spectra of electron/ion density fluctuations as described in earlier works (Chakrabarty et al., 1989; Sinha, 1992). Such spectra show a change in the spectral index at the inner scale of turbulence $\left(l_{0}\right)$, which typically is about a few tens of meters. For neutral turbulence generated fluctuations, the spectra from inner scale $l_{0}$ to outer scale or the buoyancy scale $\left(L_{B}\right)$ shows spectral index of approximately $-5 / 3$ (ISR). The region from inner scale to Kolmogorov microscale $\eta$, falls in VDR and shows a much steeper spectral index of -7 . In view of a sharp change in the spectra at the inner scale, $l_{0}$ can thus be found from the spectra. Once $l_{0}$ is determined, other turbulence parameters viz., the vertical turbulent velocity $U_{z}$, energy dissipation rate $\varepsilon$, Kolmogorov microscale $\eta$, the outer scale $L_{B}$ and the eddy diffusion coefficient $\mathrm{K}$ can been obtained using the following relations,

$\eta=l_{0} / 7.4$

$\varepsilon=v^{3} / \eta^{4}$
$K=0.81 \varepsilon / \omega_{B}^{2}$

$U_{z}=\varepsilon / 0.4 \omega_{B}$

$L_{B}=2 \pi u_{z} / 0.9 \omega_{B}$

where $v$ is the kinematic viscosity and $\omega_{B}$ is the BruntVaisala frequency, which can be obtained from models.

Using a kinematic viscosity value of $2.13 \mathrm{~m}^{2} \mathrm{~s}^{-1}$ and a Brunt-Vaisala frequency of $20 \mathrm{mHz}$, turbulence parameters were computed for four altitude ranges, for which the Heisenberg model fit yielded the inner scale unambiguously, and the same are given in Table 3. The energy dissipation rate is $1 \mathrm{~mW} / \mathrm{kg}$ in $\mathrm{R} 3$ region and increases to $200 \mathrm{mWkg}^{-1}$ in R6 region and thus shows an increasing trend with increasing altitude. The eddy diffusion coefficient and the vertical turbulent velocity also show similar trend

\subsection{Radar observations}

Most of the values of spectral width were $2 \mathrm{~ms}^{-1}$ and hence this value has been taken to estimate the energy dissipation rate using the following relation (Hocking, 1982).

$\varepsilon \approx 2.9 v^{2} f_{B}$ 


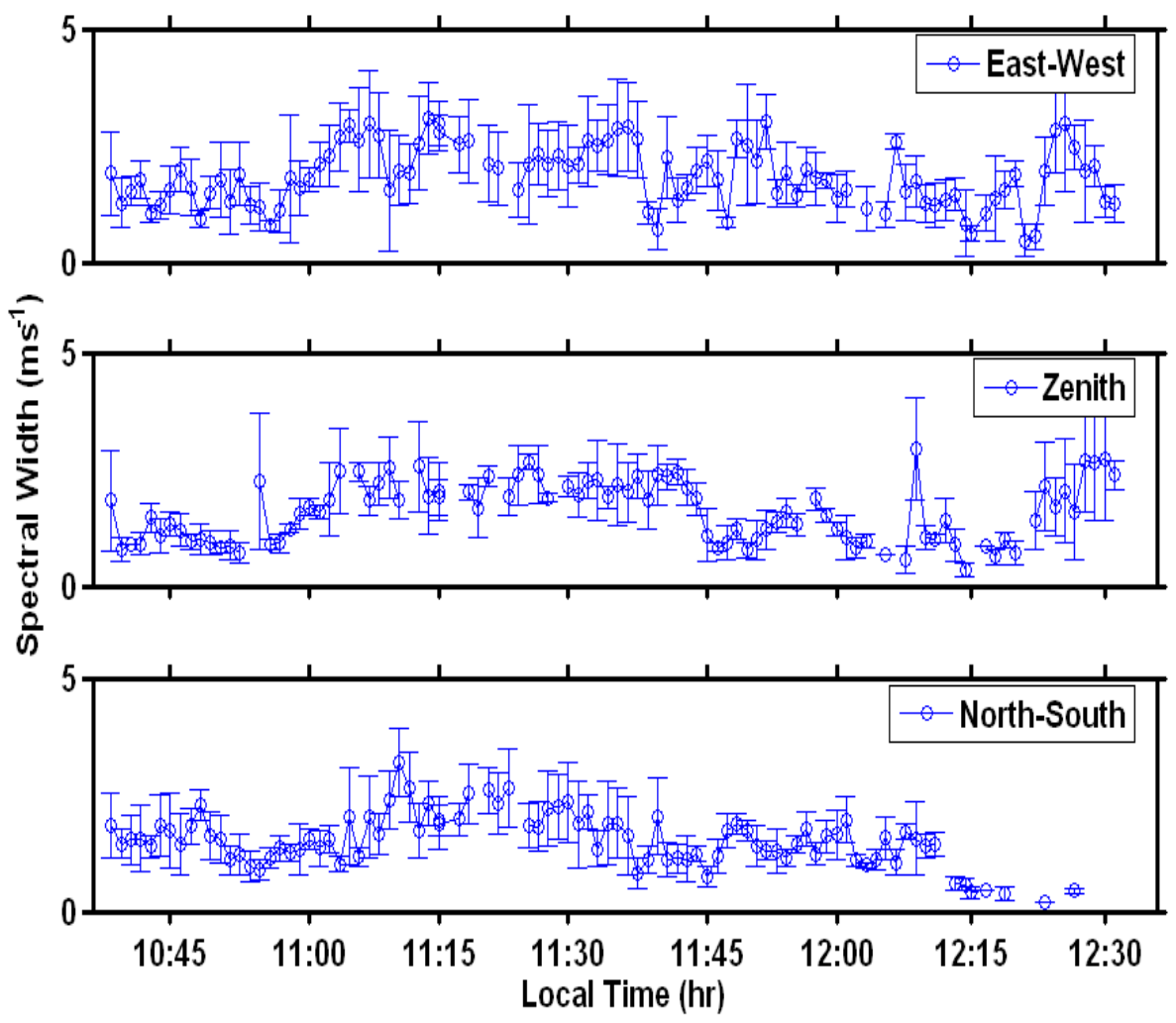

Fig. 12. Mean spectral widths along the East-West, Zenith and North-South beams on 23 July 2004.

where $f_{B}$ is the Brunt-Vaisala frequency in Hertz and $v$ is the horizontal rms velocity. The effect of the beam broadening and shear broadening has been neglected. Hocking (1982) assumed that the rms velocities are equal along vertical and horizontal directions. With this assumption, we find that for $73.5-77.5 \mathrm{~km}$ region, where the radar observed a strong scattering layer, the energy dissipation rate is $23 \mathrm{mWkg}^{-1}$ for assumed Brunt-Vaisala frequency of $20 \mathrm{mHz}$.

\section{Discussion}

Electron density measured by the rocket showed that very strong gradients were present in $67.5-71 \mathrm{~km}$, weak gradients in $71-84 \mathrm{~km}$ and moderate gradients in $84-89 \mathrm{~km}$ regions. As shown in Table 2 the percentage amplitudes of irregularities in $3 \mathrm{~m}-50 \mathrm{~m}$ scale sizes, is highest in the $67.5-$ $71 \mathrm{~km}$, modest in $84-89 \mathrm{~km}$ and smallest in $74.9-78.0 \mathrm{~km}$ region. The present observation of higher amplitude of fluctuations in regions of steeper electron density gradients is in conformity of with the results of Gallet (1955) and Villars and Weiskopf (1955), who showed that turbulent fluctuations of neutral density can be transmitted to the electron density more efficiently in presence of electron density gradients.

In view of the facts (a) that the spectra at four altitude regions fitted well with Heisenberg's model of turbulent spec- trum and spectra of the other two regions showed a slope of $-5 / 3$, (b) present as well as earlier works show that in presence of electron density gradients, fluctuations in neutral density can be transmitted to electron density more efficiently, (c) that the electron density irregularities as well as sharp gradients in electron density were present, (d) that shears in horizontal neutral winds (both zonal and meridional) which are essential for excitation of Kelvin Helmholtz instability, which leads to wave breaking and turbulence, were present, (e) that there are no known plasma instability processes at such low altitudes $(67.5-78 \mathrm{~km}$ region) which can produce the observed irregularities, it is concluded that the irregularities observed by the rocket in 67.5-71.0, $74.9-78.0 \mathrm{~km}$ and $84-89 \mathrm{~km}$ regions (R1 to R6) were produced through neutral turbulence mechanism. In R1 and R2 regions, rocket could observe the fluctuations in the ISR, whereas in R3 to R6 regions, fluctuations in both ISR and VDR regions were observed. For the altitude region 84.0$86.6 \mathrm{~km}$, scales below about $10 \mathrm{~m}$ scale size seem to have some other mechanism of generation such plasma instabilities.

The percentage amplitude of fluctuations, which is a measure of the strength of the turbulence, is large in lower altitudes and decreases with increasing altitudes (Table 2). The trend of stronger turbulence in lower altitudes can be seen for all scales from $50 \mathrm{~m}$ down to $3 \mathrm{~m}$, indicating that the 
turbulence is strong in the lower altitudes. Based on the rocket LP data of a large number of flights, Sinha (1992) had reported similar magnitude and altitude variation of the percentage amplitude for similar scale size ranges. Table 2 also shows that larger scales have higher amplitude, which also confirms the inertial nature of the spectra, where larger scales produce smaller scales.

Rocket observations also show the percentage amplitude of $3 \mathrm{~m}$ fluctuations (Table 2 ) is quite high $(2.4 \%$ and $1.6 \%$ in $\mathrm{R} 1$ and $\mathrm{R} 2$ regions) and small in $\mathrm{R} 5$ and $\mathrm{R} 6$ regions. In view of smaller density and weak strength in regions R3 and R4 regions, the percentage amplitude of $3 \mathrm{~m}$ fluctuations were below the rocket detection limit. But based on the rocket observations one can not rule out the possibility of the presence of weak $3 \mathrm{~m}$ fluctuations in R3 and R4 regions. The MST radar observations made over Gadanki, which is about $100 \mathrm{~km}$ away from Sriharikota, provide information about 3-m electron density irregularities. From the RTI plots for 23 July 2004 it is clear that the intensity of radar backscattered signal was very strong around the rocket launch time and thereafter it weakened. Around the rocket launch time, the MST radar observed strong 3-m irregularities in 73.5$76.5 \mathrm{~km}$ region (about $15 \mathrm{~dB}$ above the noise level). If we take a cue from the rocket spectra in $74.9-76.5 \mathrm{~km}$ region, the radar observations in $74.9-76.5 \mathrm{~km}$ pertain to the VDR of turbulence spectrum observed by the rocket. Thus both rocket and radar did observe $3 \mathrm{~m}$ fluctuations in a common altitude region of $74.9-76.5 \mathrm{~km}$. The sonogram, which was constructed using the LP Main channel data, also shows that the rocket observed the presence of weak irregularities (having scale sizes in excess of $10 \mathrm{~m}$ ) in the entire range. It is also possible that on either side of the common altitude region, $3 \mathrm{~m}$ fluctuations were beyond the detection limit of rocket but well within radar detection limit. Thus based on rocket and radar observations, the present work reports that $3 \mathrm{~m}$ fluctuations were present in a large range of altitudes and were very strong in the lower altitudes (R1 and R2). This result is at variance with the results of Royrvik and Smith (1984), who found $3 \mathrm{~m}$ fluctuations measured by the rocket to be in the noise floor.

The values of inner scale, Kolmogorov microscale and the outer scale of turbulence at all altitude regions observed by rocket are within the theoretical limits and similar to earlier observations (Lubken et al., 1993; Balsley and Gage, 1980).

The energy dissipation rate obtained from rocket was $1 \mathrm{~mW} / \mathrm{kg}^{-1}, 59 \mathrm{~mW} / \mathrm{kg}^{-1}, 164 \mathrm{~mW} / \mathrm{kg}^{-1}$ and $200 \mathrm{~mW} / \mathrm{kg}^{-1}$ in R3, R4, R5 and R6 regions, respectively and that obtained from radar was $23 \mathrm{~mW} / \mathrm{kg}^{-1}$ in $75-77 \mathrm{~km}$ region (which covers the same altitude region as R3 and R4 of rocket). The energy dissipation rate is small at lower altitudes and increases with altitude. Royrvik and Smith (1984) found energy dissipation rate of $50 \mathrm{~mW} / \mathrm{kg}^{-1}$ in $85.2-86.6 \mathrm{~km}$ region for Punta Lobos rocket range $\left(12.50^{\circ} \mathrm{S}, 76.80^{\circ} \mathrm{W}\right)$, which like Sriharikota is a low latitude station. Lehmacher et al. (2006) reported a value of $170 \mathrm{~mW} / \mathrm{kg}^{-1}$ in $92-96 \mathrm{~km}$ region over Roi-Namur, Kwajalein Atoll, Marshall Islands $\left(9^{\circ} \mathrm{N}, 168^{\circ} \mathrm{E}\right)$. Energy dissipation rates even in high latitudes (Lubken, 1997), were about $150 \mathrm{~mW} / \mathrm{kg}^{-1}$ in $90 \mathrm{~km}$ region. Although, the order of magnitude of the energy dissipation rates, presented here are similar to the earlier work, the values appear to be slightly higher. This could be due to the fact that the day of rocket observations was a magnetically disturbed day. It is well known that during disturbed days gravity waves of auroral origin can reach low latitudes and can enhance the turbulent activity and hence the energy dissipation rate. It can be seen from the spectra in $67.5-71.0 \mathrm{~km}$ region, the energy dissipation scales are below 3-m indicating that the turbulent kinetic energy dissipation rate in 67.5$71.0 \mathrm{~km}$ region is possibly not very important in this region. This also support the observation of small values found in lower altitudes.

In this context, the radar observations can be used for further insight. Radar echoes are confined to mostly 73.5$77.5 \mathrm{~km}$ and down to $70 \mathrm{~km}$ during 14:45-15:15 LT. And no echoes were observed above $78 \mathrm{~km}$ in contrast to electron density structures observed in the height region of $84-89 \mathrm{~km}$ by the rocket probe. Considering that the height region of radar echoes is close to the lower altitude region of electron density structures observed in rocket observations, radar observations can be related to electron density gradients of some sort. For horizontally stratified vertical electron density gradient, the radar echoes are supposed to be observed only by vertical beam. The fact that the radar echoes were observed in all beams indicates that some amount of turbulence would have been present to provide electron density fluctuations, which were present in all beam directions. On the other hand SNR observed by different beams are found to be different and in general west, zenith and north beam SNR are found to be more than that of east and south beam. This observation is indicative of aspect sensitivity of the radar echoes. Thus both radar and rocket observations seem to agree broadly in terms of steep density gradient being responsible for the observed features.

The detection of turbulence in $\mathrm{R} 1$ and $\mathrm{R} 2$ regions and no such detection by the radar points to the possibility that turbulence layers might be thinner than $450 \mathrm{~m}$, which is the radar altitude resolution. In fact existence of thin layers of turbulence with thickness as small as $100 \mathrm{~m}$ on either side of a thick turbulent layer has been predicted by direct numerical simulation (DNS) studies (Fritts et al., 2003). Thus the present observations point towards the existence of thin layers of turbulence.

Also the 10 min periodicity found in radar derived zonal and meridional winds in $73.5-76.5 \mathrm{~km}$ region suggests the presence of gravity waves of that period, whose amplification during their upward passage and eventual breaking could be responsible for the turbulence observed by the rocket in regions 74.9-89 km (R3 to R6). As observed by the Chaff experiment, the shears in both the zonal and meridional winds were also very strong over Sriharikota in $70-76 \mathrm{~km}$ altitude 
range around the rocket launch time. If the strong wind shears produced turbulence due to Kelvin Helmholtz instability, the gradients in electron density would enhance the production efficiency of electron density irregularities due to high electron-neutral collision frequency. Thus the of MST radar echoes in $73.5-76.5 \mathrm{~km}$ might have been due to the turbulence resulting due to shear instability. Earlier rocket observations (Sinha, 1992) showed that at altitudes above $80 \mathrm{~km}$, time scale of dissipation of $3 \mathrm{~m}$ irregularities is small as these irregularities fall in the VDR. Due to this, formation of discrete layer above $80 \mathrm{~km}$ altitude would be difficult. The present MST radar observations of layered structures up to $77.5 \mathrm{~km}$ only are in conformity with the present and earlier rocket observations. This could also be the reason of weaker fluctuations observed for all scale by the rocket in $84-89 \mathrm{~km}$ regions.

\section{Summary}

Electron density fluctuations from $50 \mathrm{~m}$ down to $3 \mathrm{~m}$ scale size were observed in $67.5-78.0 \mathrm{~km}$ and $84-89 \mathrm{~km}$ regions by the rocket during its ascent. These scales cover a substantial part of the ISR and some part of the VDR at these altitudes.

In view of (a) the shape of the spectra of the fluctuations matched very well with the characteristic turbulent spectrum showing a slope of $-5 / 3$ in the ISR and gradually going to a slope of -7 in the VDR, (b) the presence of shears in zonal and meridional winds, which are essential for the excitation of the Kelvin Helmholtz instability and subsequent wave breaking and generation of neutral turbulence, (c) the presence of electron density gradients, which transmit the neutral fluctuations to electrons more efficiently and (d) the absence of any plasma instability which possibly can operate at such low altitudes, it is concluded that the irregularities observed by the rocket were produced by the mechanism of neutral turbulence.

Turbulence parameters such as the scales of turbulence (outer scale, inner scale and Kolmogorov microscale), energy dissipation rate, eddy diffusion coefficient and vertical turbulent velocity were calculated from the spectra observed by the rocket at six altitude ranges and these were found to be within the theoretical limits and in agreement with the earlier studies.

The amplitudes of fluctuations at all scale sizes in the lower altitudes were much larger than those in the upper altitude indicating stronger turbulence in lower altitude regions. Higher amplitude of irregularities in the lower altitude regions is commensurate with the higher electron-neutral collision frequency and sharper electron density gradients present in this altitude region as well as expected higher degree of turbulence as compared to $74.9-78.0 \mathrm{~km}$ and $84-89 \mathrm{~km}$ regions, which are much closer to the turbopause altitude.

The 3-m fluctuations observed by the rocket were quite strong in $67.5-71.0 \mathrm{~km}$ region and moderate but well above the noise floor in $86.6-89.0 \mathrm{~km}$ region. As observed by the MST radar, the 3-m irregularities were found to be present in 73.5-76.5 km region from 10:30 to 16:00 LT, around 65$67 \mathrm{~km}$ region during 09:30 to 10:30 LT in and in $68-70 \mathrm{~km}$ around 13:25 LT. In view of the facts that this region is conducive to the excitation of the Kelvin Helmholtz instability, the required wind shears for the excitation of KHI were observed by Chaff and that no other plasma instability can possibly operate at such low altitudes, it is concluded that the observed irregularities were produced by the neutral turbulence mechanism. The zonal and meridional winds measured by the radar in $75-77 \mathrm{~km}$ region showed the presence of a 10-min periodicity, which pointed towards the presence of gravity waves at those altitudes. It is possible that these gravity waves got amplified during their upward passage and their breaking produced turbulence. The detection of turbulent fluctuations in $84-89 \mathrm{~km}$ altitude region by the rocket, substantiate this possibility.

The amplitude of the turbulent fluctuations at all scales was found to be high (low) when the electron density gradients were strong (weak) as predicted by earlier studies.

Both radar and rocket observations indicate that the thickness of the turbulent layers lies between $3 \mathrm{~km}$ to $5 \mathrm{~km}$. The multi-beam radar observations show the existence of turbulence layer thicknesses as small as $1 \mathrm{~km}$ or less. The detection of turbulence in lower regions $(67.5-71.0 \mathrm{~km}$ by rocket and no detection by radar points towards the possible presence of layers thinner than $450 \mathrm{~m}$. Layers as thin as $100 \mathrm{~m}$ have been predicted by direct numerical simulation studies.

Acknowledgements. The authors thank the Physical Research Laboratory, Ahmedabad and the Indian Space Research Organisation (ISRO), Bangalore for funding this project. Many useful discussions with B. H. Subbaraya are thankfully acknowledged. Thanks are also due to the RSR group of VSSC, Trivandrum and SDSC, SHAR for payload integration and necessary launch support. Authors wholeheartedly appreciate the effort of the NARL technical team for successfully conducting the experiments with the MST radar.

Topical Editor M. Pinnock thanks three anonymous referees for their help in evaluating this paper.

\section{References}

Balsley, B. B. and Gage, K. S.: The MST Radar Technique: Potential for Middle Atmospheric Studies, Pageoph, 18, 453-493, 1980.

Blood, S. P., Mitchell. J. D., Croskey. C. L., Raymund, T. D., Thrane, E. V., Blix, T. A., Hopp, U. V., Fritts, D. C., and Schmidlin, F. J.: Studies of high latitude mesospheric turbulence by radar and rocket 2 : measurements of small scale turbulence, J. Atmos. Terr. Phys., 50, 963-976, 1988.

Chakrabarty, D. K., Beig, G., Sidhu, J. S., and Das, S. R.: Fine scale structure and turbulence parameters in the equatorial middle atmosphere, J. Atmos. Terr. Phys., 51, 19-27, 1989.

Chakravarty, S. C., Datta Jayati, Kamala, S., and Gupta, S. P.: High-resolution mesospheric layer structures from MST radar 
backscatter echoes over low latitude, J. Atmos. Sol. Terr. Phys., 66, 859-866, 2004.

Chakravarty, S. C., Datta Jayati, and Revankar, C. P.: Climatology of long period oscillations in the equatorial middle atmosphere over Thumba, India, Curr. Sci., 63, 33-42, 1992.

Datta Jayati, Chakravarty, S. C., and Prasad, B. S. N.: Indian MST radar-mesospheric studies, Curr. Sci., 81, 661-666, 2001.

Fritts, D. C.: Gravity wave saturation in the middle atmosphere: a review of theory and observations, Rev. Geophys. Space Phys., 22, 275-308, 1984.

Fritts, D. C., Bizon, C., Werne, J. A., and Meyer, C. K.: Layering accompanying turbulence generation due to shear instability and gravity-wave breaking, J. Geophys. Res., 108, 8452, doi:10.1029/2002JD002406, 2003.

Gage, K. S. and Balsley, B. B.: On the scattering and reflection mechanisms contributing to clear air radar echoes from the troposphere, stratosphere and mesosphere, Radio Sci., 15, 243-257, 1980.

Gallet, R. M.: Aerodynamical mechanism producing electron density fluctuations in turbulent ionized layers, Proc. IRE, 43B, 1240-1252, 1955.

Goldberg, R. A., Fritts, D. C., Chou, H. G., Barcus, J. R., and Schmidlin, F. J.: Studies of high latitude mesospheric turbulence by radar and rocket 1 . energy deposition and wave structure, J. Atmos. Terr. Phys., 50, 951-961, 1988.

Goldberg, R. A., Lehmacher, G. A., Schmidlin, F. J., Fritts, D. C., Mitchell, J. D., Croskey, C. L., Friedrich, M., and Swartz, W. E.: Equatorial dynamics observed by rocket, radar and satellite during the CADRE/MALTED campaign:1. Programmatics and small-scale fluctuations, J. Geophys. Res., 102, 26 179-26 190, 1997.

Heisenberg, W.: Zur stastischen Theorie der Turbulenz, Z. Phys., 124, 628-657, 1948.

Hocking, W. K.: On the extension of atmospheric turbulence parameters from radar backscatter Doppler spectra, 1, Theory, J. Atmos. Terr. Phys., 45, 89-102, 1982.

Kamala, S., Narayana Rao, D., Chakravarty, S. C., Datta Jayati, and Prasad, B. S. N.: Vertical structure of mesospheric echoes from the Indian MST radar, J. Amos. Sol. Terr. Phys., 65, 71-83, 2003.

Kumar, G. K., Ratnam, M. V., Patra, A. K., Rao, V. V. M. J., Rao, S. V. B., and Rao, D. N.: Climatology of the low-latitude mesospheric echo characteristics observed by Indian MST Radar, J. Geophys. Res., 112, D06109, doi:10.1029/2006JD007609, 2007.

Kubo, K., Sugiyama, T., Nakamura, T., and Fukao, S.: Seasonal and interannual variability of mesospheric echoes observed with the Middle and Upper Atmosphere radar during 1986-1995, Geophys. Res. Lett., 24, 1211-1214, 1997.

Lehmacher, G. A., Croskey, C. L., Mitchell, J. D., Friedrich, M., Lubken, F.-J., Rapp, M., Kudeki, E., and Fritts, D. C.: Intense turbulence observed above a mesospheric temperature inversion at equatorial latitude, Geophys. Res. Lett., 33, L08808, doi:10.1029/2005GL024345, 2006.
Lubken, F.-J., Hillert, W., Lehmacher, G., and von Zahn, U.: Experiments revealing small impact of turbulence on energy budget of the mesosphere and lower thermosphere, J. Geophys. Res., 98, 20369-20 384, 1993.

Lubken, F.-J.: Seasonal variation of turbulent energy dissipation rates at high latitudes as determined by in situ measurements of neutral density fluctuations, J. Geophys. Res., 102, $13441-$ $13456,1997$.

Prakash, S., Gupta, S. P., and Subbaraya, B. H.: Cross Field Instability and Ionization Irregularities in the Equatorial E region, Nature Phys. Sciences, 230(16), 170-171, 1971.

Prakash, S., Gupta, S. P., Subbaraya, B. H., and Pandey, R.: A review of the electron density irregularities in the equatorial D \& E region, Adv. Space Explorations, 8, 3-16, 1980.

Prakash, S. and Subbaraya, B. H.: Langmuir Probe for the measurement of electron density and electron temperature in the ionosphere, Rev. Sci. Inst., 38(8), 1132-1136, 1967.

Rao, P. B., Jain, A. R., Kishore, P., Balamuralidhar, P., Damle, S. H., and Viswanathan, G.: Indian MST Radar I. System description and sample vector wind measurements in ST mode, Radio Sci., 30, 1125-1138, 1995.

Royrvik, O. and Smith, L. G.: Comparison of mesospheric VHF radar echoes and rocket probe electron concentration measurements, J. Geophys. Res., 89, 9014-9022, 1984.

Sasi, M. N. and Vijayan, L.: Turbulence characteristics in the tropical mesosphere as observed by MST radar at Gadanki $\left(13.5^{\circ} \mathrm{N}\right.$, 79.2 ${ }^{\circ}$ E), Ann. Geophys., 19, 1019-1025, 2001, http://www.ann-geophys.net/19/1019/2001/.

Sinha, H. S. S.: Studies in Equatorial Aeronomy, Ph. D. thesis, Gujarat University, Ahmedabad, India, 1976.

Sinha, H. S. S.: Plasma density irregularities in the equatorial Dregion produced by neutral turbulence, J. Atmos. Terr. Phys., 54, 49-61, 1992.

Sinha, H. S. S. and Prakash, S.: Rocket observations of E-region ionization irregularities produced through cross field instability mechanism - current status, Ind. J. Radio Space Phys., 16, 102113, 1987.

Thrane, E. V. and Grandal, B.: Observations of fine scale structure in the mesosphere and lower thermosphere, J. Atmos. Terr. Phys., 43, 179-189, 1981.

Thrane, E. V., Andreassen, O., Blix, T. A., Grandal, B., Brekke, A., Philbrick, C. R., Schmidlin, F. J., Widdel, H. U., von Zahn, U., and Lubken, F. J.: Neutral air turbulence in the upper atmosphere observed during the energy budget campaign, J. Atmos. Terr. Phys., 47(1), 243-264, 1985.

Thrane, E. V., Blix, T. A., Hall, C., Hansen, T. L., von Zahn, U., Meyer, W., Czechowsky, P., Schmidt, G., Widdel, H.-U., and Neumann, A.: Small scale structure and turbulence in the mesosphere and lower thermosphere at high latitudes in winter, J. Atmos. Terr. Phys., 49(7/8), 751-762, 1987.

Villars, F. and Weisskopf, V. F.: On the scattering of radio waves by turbulent fluctuations of the atmosphere, Proc. IRE, 43B, 1232$1239,1955$. 